Full length article

\title{
Cross-aisle stiffness analysis of industrial welded cold-formed steel rack upright frames
}

\author{
Francesc Roure ${ }^{\mathrm{a}, *}$, Teoman Peköz ${ }^{\mathrm{b}}$, M. Rosa Somalo ${ }^{\mathrm{a}}$, Jordi Bonada ${ }^{\mathrm{a}}$, M. Magdalena Pastor ${ }^{\mathrm{a}}$, \\ Amadeu Segura ${ }^{a}$ \\ ${ }^{\text {a }}$ RMEE, ETSEIB, Universitat Politècnica de Catalunya, Spain \\ ${ }^{\mathrm{b}}$ Cornell University, USA
}

\section{A B S T R A C T}

In general, industrial cold-formed steel pallet racks consist of upright frames and pallet beams. In the United States, typically, the upright frames are made welding the braces to the uprights. If the brace to upright joints are considered as rigid joints, the stiffness of welded upright frames in the cross-aisle direction obtained numerically is very different from the stiffness obtained experimentally (up to $300 \%$ higher). A method is proposed to improve the accuracy of the numerical determination of the stiffness of the frames, by taking into account the semi-rigid behaviour of the brace to upright joints. The semi-rigid behaviour of the joints is analysed experimentally and by simulation with finite elements. The method proposed uses linear behaviour approximation of the frame, and obtains a numerical stiffness that differs only by $10 \%$ of the experimental stiffness.

\section{Introduction}

In general, industrial cold-formed steel pallet racks consist of upright frames and pallet beams. Upright frames consist of uprights, upright base plates and bracing members. In the United States, typically, base plates and braces are welded to the uprights. Usually the uprights are cold formed steel lipped channels. A typical example of frame is shown in Fig. 1.

The stability of the rack is usually analysed in both directions: down-aisle and cross-aisle. In the down-aisle direction, stability relies on the beam to upright connections and the upright to floor connections. Several authors have studied the nonlinear behaviour of beamupright connections, as well as how to model them (See Refs. [1-11]). In the cross-aisle direction, stability relies on the stiffness of the upright frames. In this type of frame, the axes of the uprights and the braces are all in the same plane, and a plane frame analysis may model correctly the behaviour of the frame, provided that the behaviour of the upright to brace joint is properly represented.

S. Sambasiva et al. established a similar conclusion in 2004 [12]. In 2008, S.R. Sajja et al. [13] analysed the cross-aisle stiffness of bolted rack braced frames, and have found that the local flexibility of the joints is very important when trying to build an FE model of the frame. The ANSI code MH 16.1: 2008 [14] developed by RMI for the design of rack structures, recommends also in paragraph 6.3 .4 to take into consideration, for the analysis of joints, the deformation of the members legs, lips and stiffening elements. In 2012 B P. Gilbert et al. [15] analysed the shear behaviour of bolted rack braced frames experimentally and with FE models, with two different load schemes, and concluded that the transverse load method reproduces better the actual working behaviour of the frame, and that the local flexibility of the joints has great importance in the modelling of the frame. In 2015, F. Roure et al. [16] have also established the importance of local flexibility of the joints of the braces to uprights in an experimental and FE analysis of the down-aisle stiffness of shelving structures with diagonal bracing. As shown by F. Roure et al. in Refs. [17,18], an analysis of welded rack braced frames, made using a rigid joint model, shows a stiffness several times greater than the stiffness of the actual frame, obtained experimentally. In 2017 H. Far et al. [19] have tested bolted rack braced frames, experimentally and with FE models, and have improved the FE models by reducing the axial stiffness of the braces, to reproduce the effect of the flexibility of the joints.

The semi-rigid nature of the joints results from the distortions of the column at the connections to the braces. Rotational flexibility at the joints does not have as significant effect as the stiffness in the axial direction of the braces. However, the axial stiffness of the braces is reduced significantly due to the distortions of the columns at the joints.

\footnotetext{
* Corresponding author.

E-mail address: francesc.roure@upc.edu (F. Roure).
} 

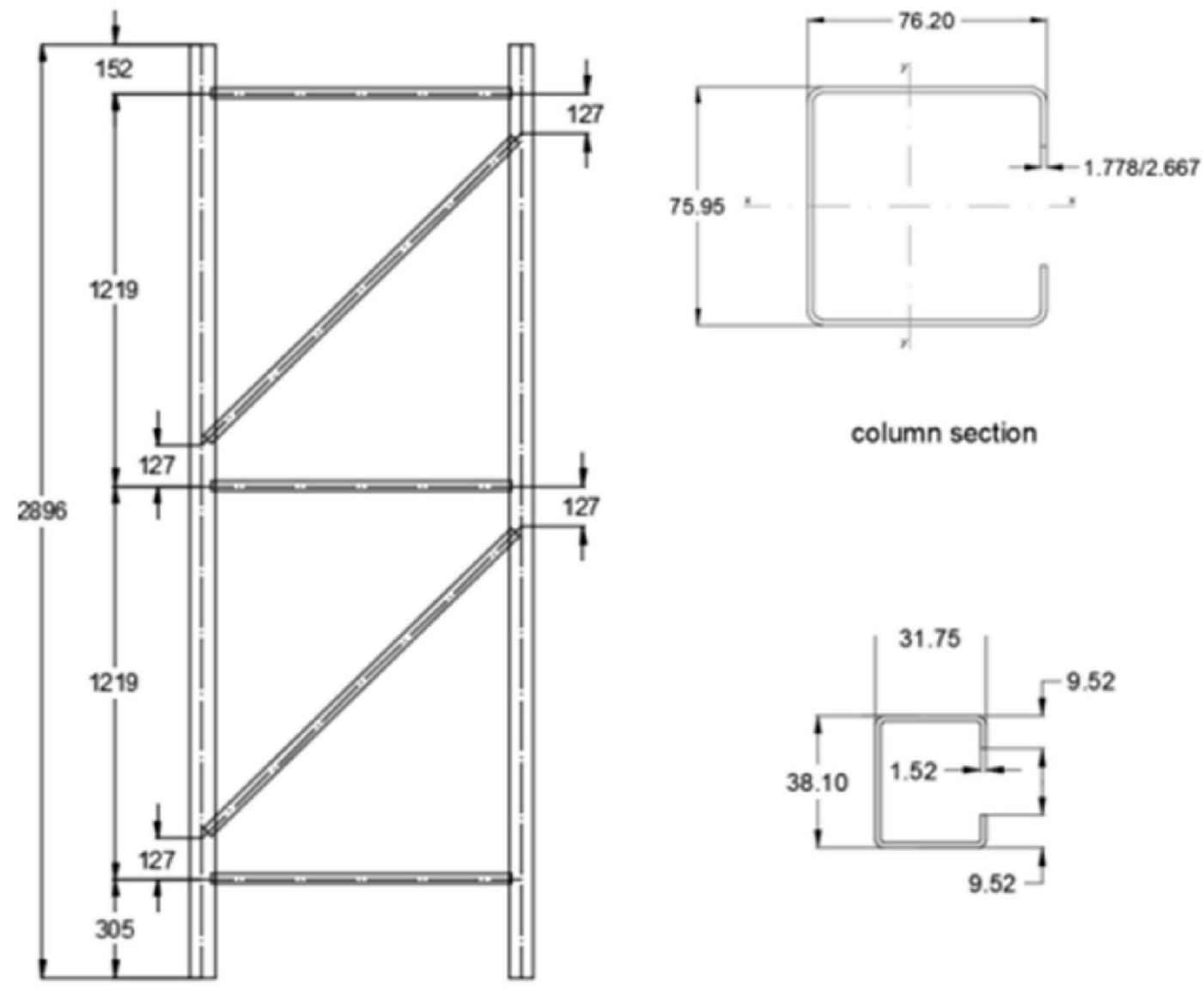

column section

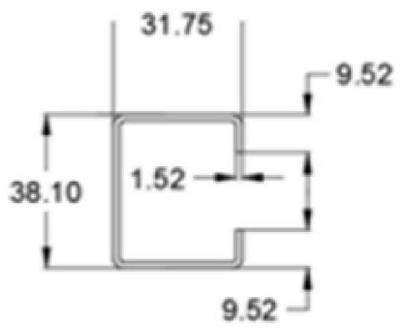

brace section

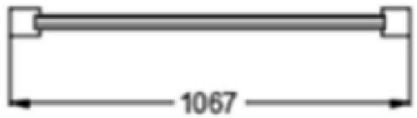

Fig. 1. Frame geometry. (Dimensions in $\mathrm{mm}$ ).

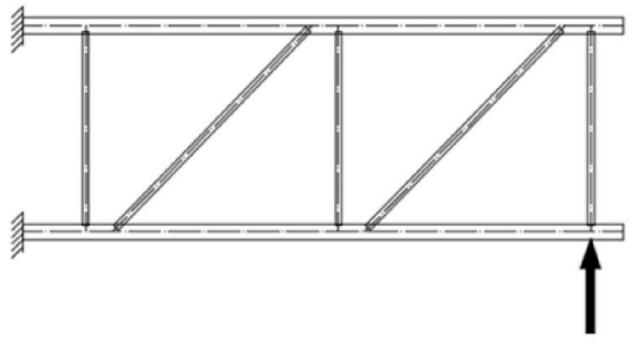

a) Diagonals in tension - DT

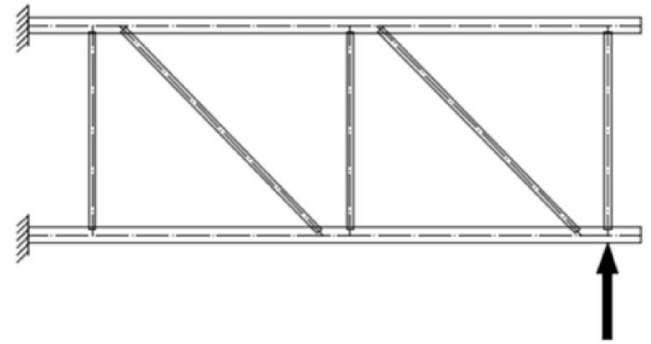

b) Diagonals in compression - DC

Fig. 2. The two load schemes applied to the frames.

The stiffness and strength of the joints between the braces and columns were studied experimentally and analytically as reported by F. Roure et al. in Ref. [15].

To develop a simple and more accurate approach to the design of upright frames as semi-rigid frames tests were carried out at LERMA (Laboratory of Elasticity and Resistance of Materials), Universitat Politècnica de Catalunya, Barcelona, Spain. 


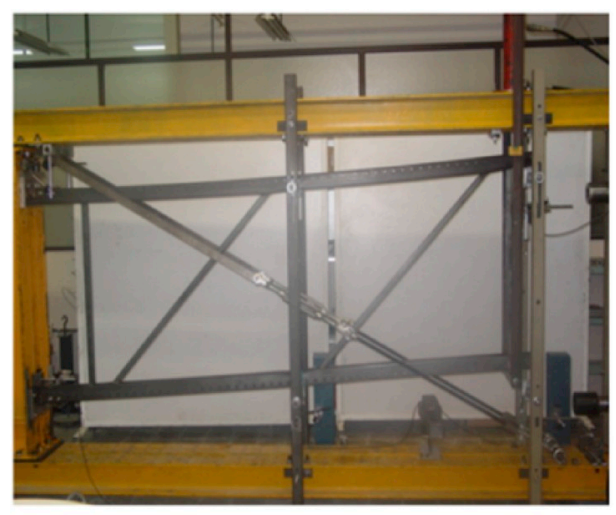

a) Diagonals in tension - DT

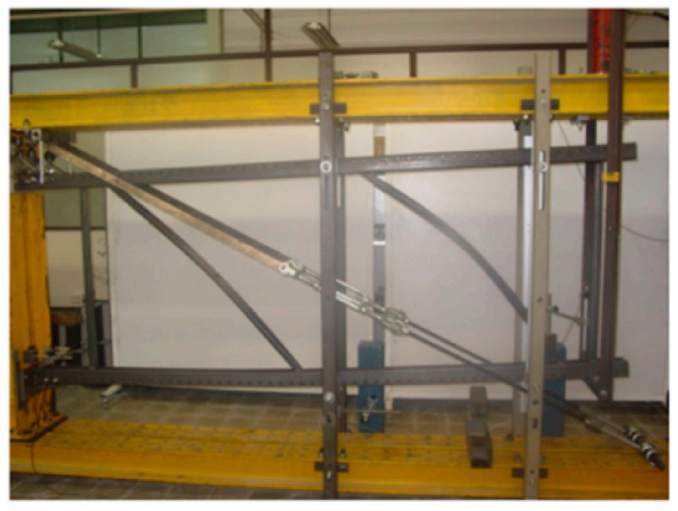

b) Diagonals in compression - DC

Fig. 3. Test set-up.

Table 1

Material properties (mean values).

\begin{tabular}{lll}
\hline Member & $\mathrm{f}_{\mathrm{yd}}(\mathrm{MPa})$ & $\mathrm{f}_{\text {ult }}(\mathrm{MPa})$ \\
\hline Column F70 & 515 & 591 \\
Column F77 & 427 & 479 \\
Brace & 445 & 515
\end{tabular}

\section{Frame testing}

Typical upright frame shown in Figs. 1-3 were chosen for testing. Two types of frame have been tested. The frames have the same geometry (height $=2896 \mathrm{~mm}$, width $=1067 \mathrm{~mm}$ ) but the columns are different. The members provided by Mecalux S.A. have the following sections. Frame F70 has columns that are lipped C sections $75.95 \times 76.20 \times 1.78 \mathrm{~mm}$, and frame F77 has lipped C section $75.95 \times 76.20 \times 2.67 \mathrm{~mm}$ columns. For both frames the bracing are lipped C sections $38.10 \times 31.75 \times 1.52 \mathrm{~mm}$. Material properties were obtained by tensile tests of 4 coupons extracted of each type of section. Mean values are shown in Table 1 . The braces are welded to the columns at an angle of $90^{\circ}$ and $45^{\circ}$ as shown in Figs. 1-3. In all the tests the fixed ends of the columns have all the degrees of freedom restricted, and the frame is laterally guided, so that it can move free only in its own plane.

The force is applied with a hydraulic jack and is measured with a force transducer. The vertical displacement at the free end of the frame is measured with displacement transducers. The signals are digitized and recorded in a computer.

Each frame was also subjected to two types of loading, one that will cause tension in the diagonals and the other compression. Tests were done on three identical frames for each type of upright and loading. Thus, there were 12 tests in total. Though the tests were done on rather low height upright frames, it is expected the developed methodology will be applicable to higher upright frames.

\section{Rigid frame analysis of the test frames}

In Ref. [7], the authors carried out frame analyses using MASTAN2 program. In this phase of the research ANSYS V14 software has been used. The results using MASTAN2 and ANSYS V14 are in agreement.

Finite Element Method (FEM) analysis in this phase of research with ANSYS V14 has used Beam 188 elements. Beam 188 is 2-node 3D beam element based on Timoshenko beam theory. It has six degrees of freedom for each node (three displacements and three rotations). The gross cross section properties have been used. In the frames tested, the failure was buckling of the braces, for the "diagonals in compression" test set-up; or local buckling in the horizontal brace-upright joint, for the "diagonals in tension" test set-up. In both cases, the failure occurs at a sway displacement of the frames of $85 \mathrm{~mm}$ minimum (see Fig. 4), much higher than $\mathrm{H} / 200=14.5 \mathrm{~mm}$, which has been considered the maximum sway for service limit. Since our interest was in determining the stiffness of the frames under this limit value (under a displacement of $14,5 \mathrm{~mm}$ ), there was no need to consider eventual buckling phenomena or non linear behaviour, because they do not appear. Thus material and geometrical behaviour were assumed to be linear to study the initial behaviour of the frame.

The joints are modelled at first as rigid. Results of the analyses are presented in Fig. 4. The graph relates the displacement of the node where the force is applied, with the force. "Exp" are the curves obtained in each of the three tests. "Exp. sec" is the secant line from origin to the point of the graph, mean of the three tests, corresponding to a displacement of the node of $\mathrm{H} / 200=14.5 \mathrm{~mm}$, where $\mathrm{H}$ is the distance from the column base to the point of application of the lateral load. "ANSYS rigid" is the stiffness obtained with the rigid frame FEM model. Table 2 shows the stiffness of the frames obtained experimentally and the stiffness obtained by the rigid frame analysis. It can be seen that the stiffness of the rigid frame analysis, designated "ANSYS rigid", is always much higher than the stiffness of the corresponding test results (2.5-4 times higher).

It was observed in Ref. [7] that accounting for the axially semi-rigid nature of the column to brace joints gives much better correlation with the experimental results. For this reason, column to brace joints are 


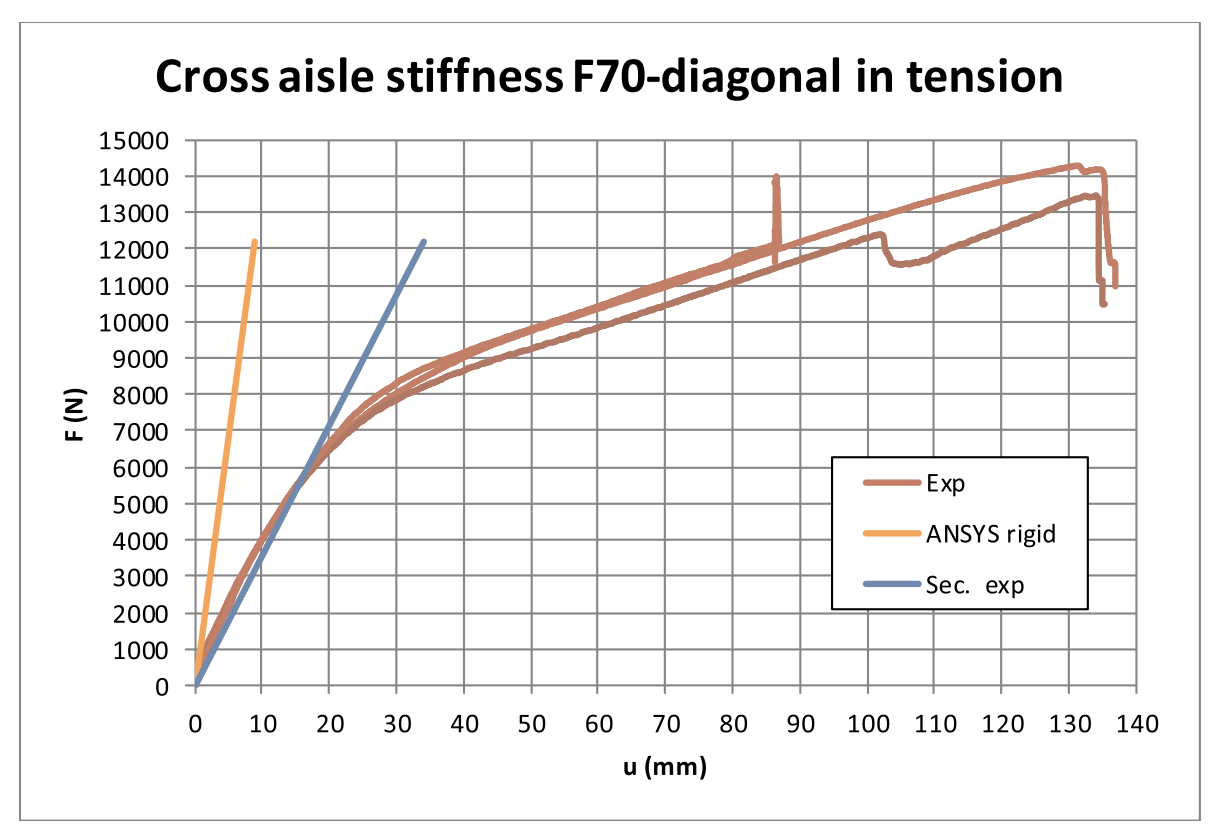

a) Diagonals in tension

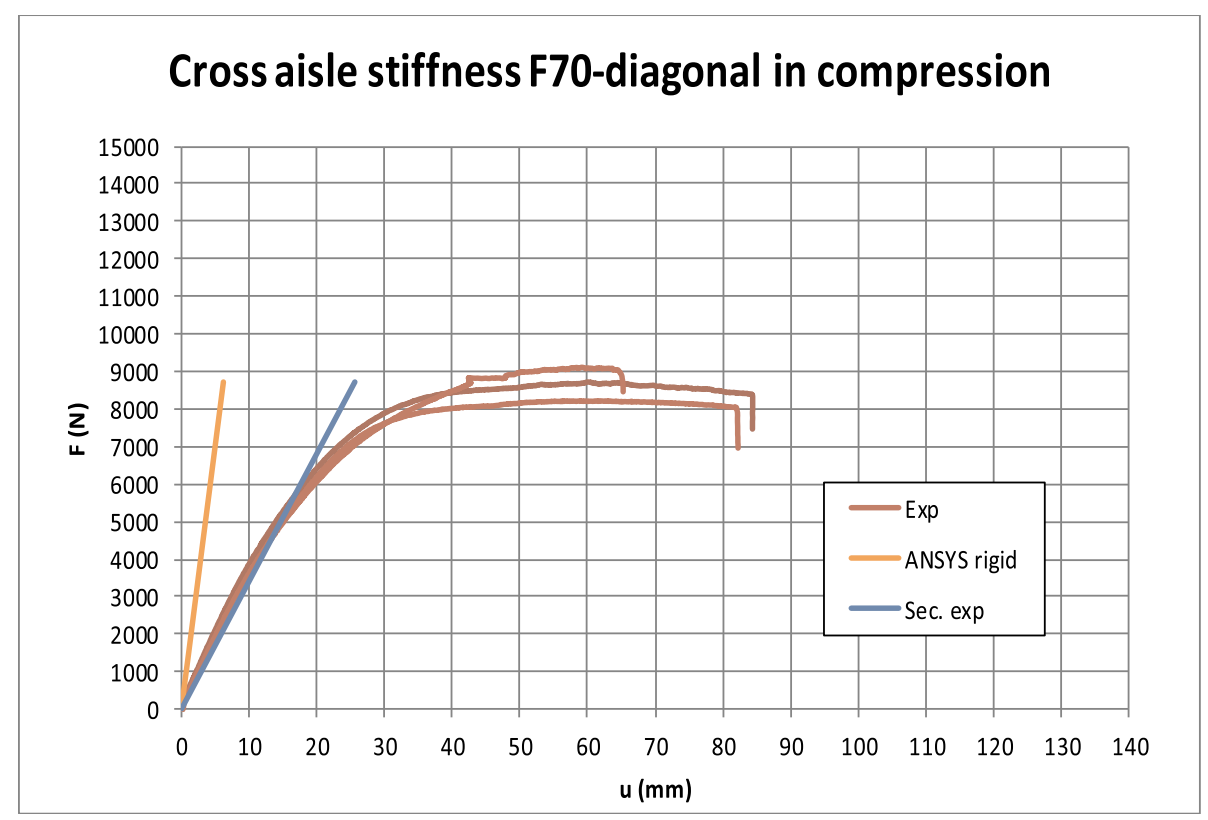

b) Diagonals in compression

Fig. 4. Cross aisle stiffness: experimental and calculated results.

Table 2

Experimental and computed stiffness of the frames.

\begin{tabular}{|c|c|c|c|c|}
\hline Upright & Case & $\mathrm{K}_{\text {experimental }}(\mathrm{N} / \mathrm{mm})$ & $\mathrm{K}_{\mathrm{FE} \text { rigid }}(\mathrm{N} / \mathrm{mm})$ & $\mathrm{K}_{\mathrm{FE}, \mathrm{r}} / \mathrm{K}_{\exp }$ \\
\hline \multirow[t]{2}{*}{ F70 $(1.78 \mathrm{~mm})$} & Diagonals in tension - DT & 358 & 1343 & 3.8 \\
\hline & Diagonals in compression - DC & 356 & 1402 & 3.9 \\
\hline \multirow[t]{2}{*}{ F77 $(2.67 \mathrm{~mm})$} & Diagonals in tension - DT & 635 & 1607 & 2.5 \\
\hline & Diagonals in compression - DC & 657 & 1692 & 2.6 \\
\hline
\end{tabular}




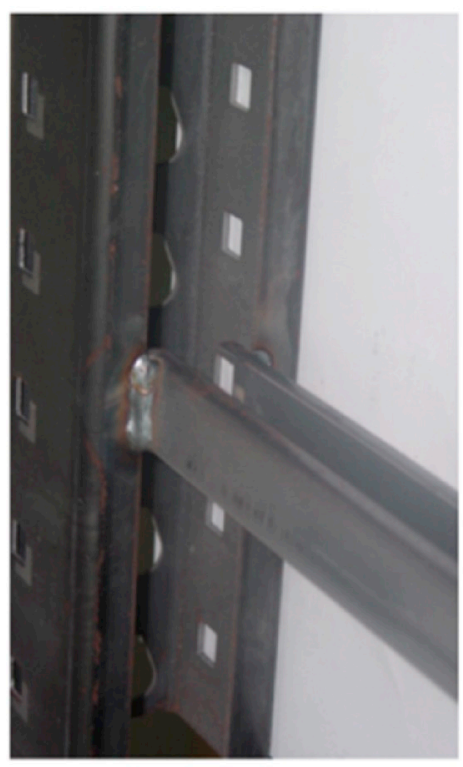

$90^{\circ}$ Joint

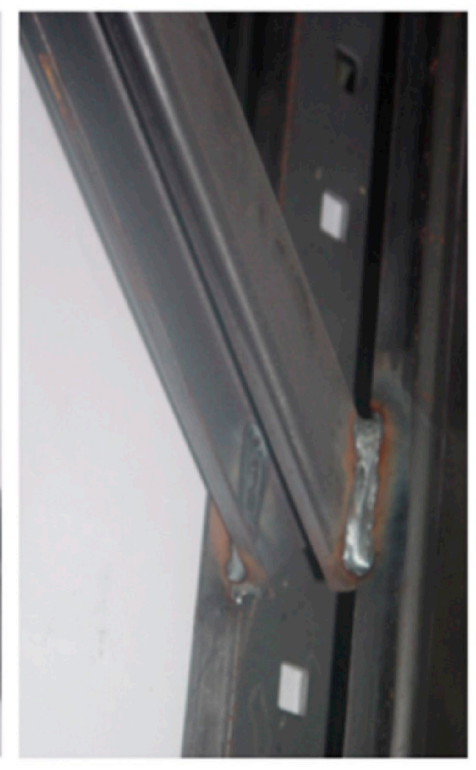

$+45^{\circ}$ Joint

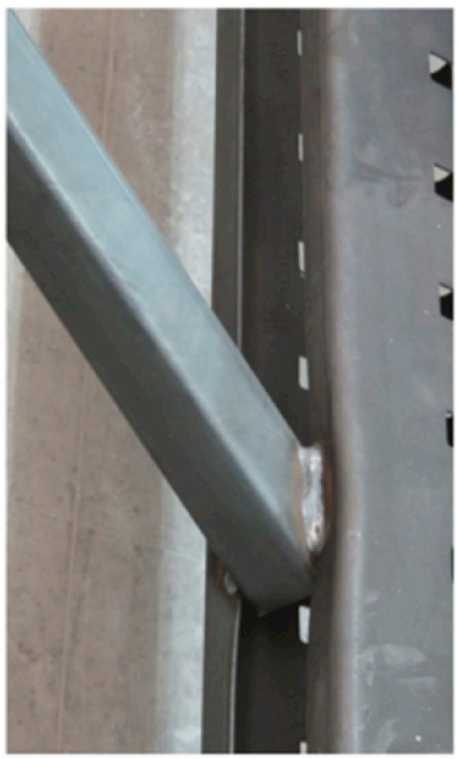

$-45^{\circ}$ Joint

Fig. 5. Brace to column joints.

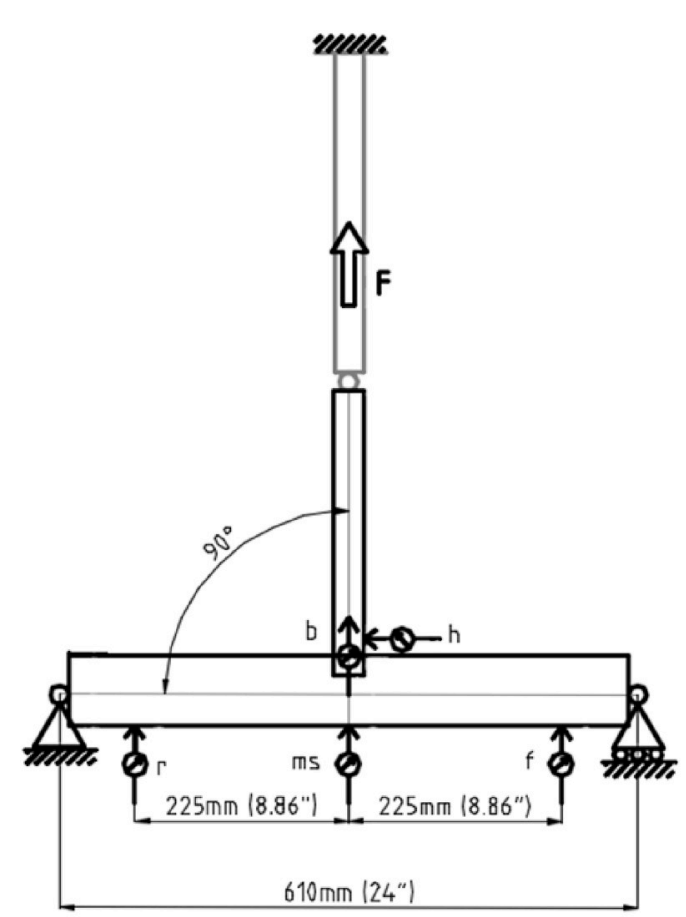

a) $90^{\circ}$

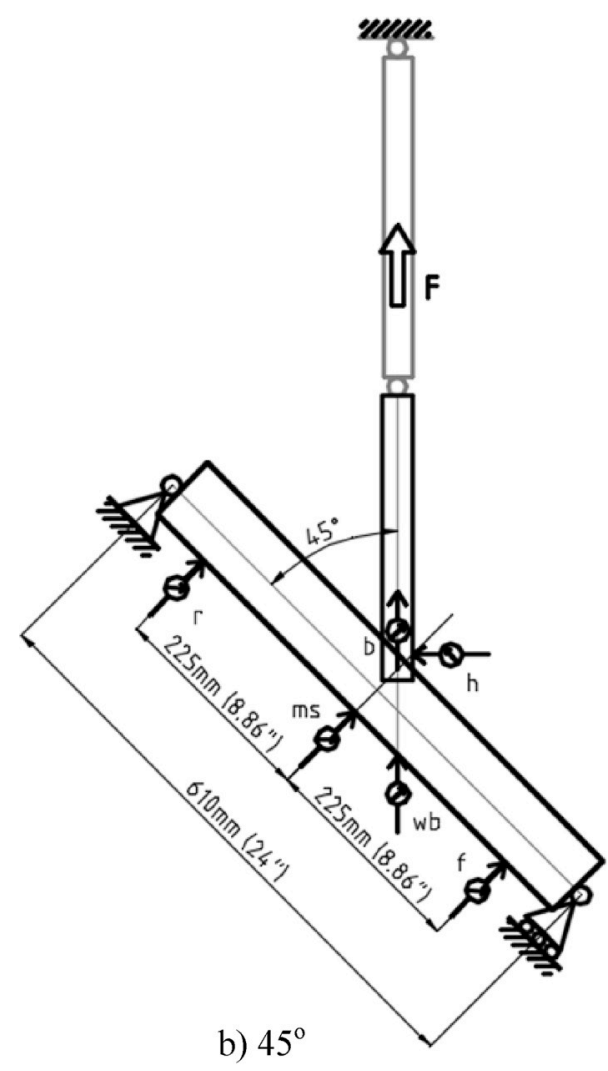

b) $45^{\circ}$

Fig. 6. Joint test setups. 


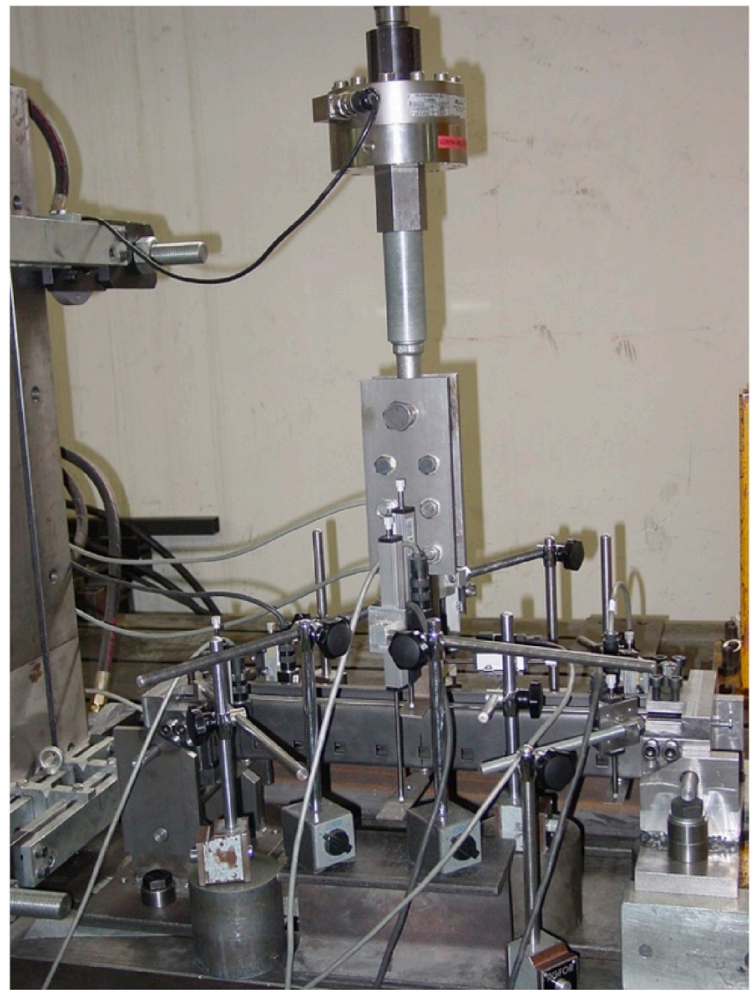

Fig. 7. Details of instrumentation for the $90^{\circ}$ test.

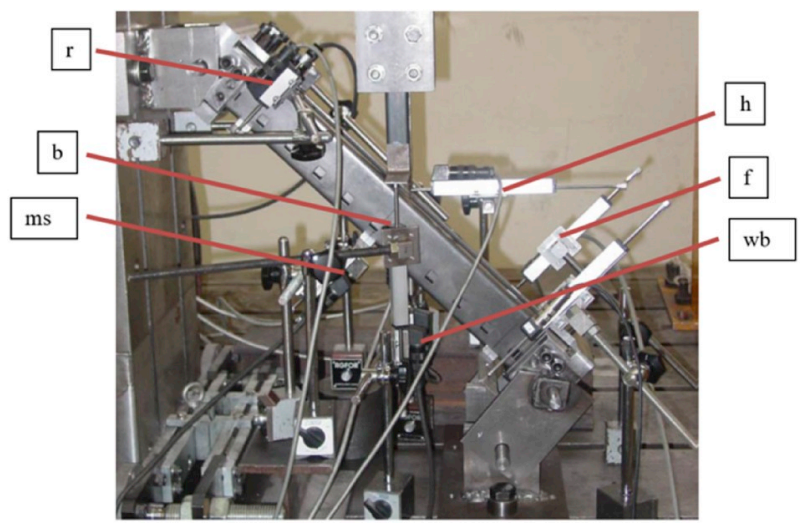

Fig. 8. Detail of instrumentation for the $+45^{\circ}$ test.

studied experimentally and analytically.

\section{Joint tests}

All the joints of braces to columns shall be referred to as joints in this study. Joints can be classified, with respect to the geometry, into two groups: joints with an angle between brace and upright of $90^{\circ}$, and joints with an angle of $45^{\circ}$ (see Fig. 5). The braces of the frames tested have a $\mathrm{C}$ section, and the two joints of a $45^{\circ}$ brace are not identical: one joint has the web of the $\mathrm{C}$ section at the inside of the $45^{\circ}$ angle, and it will be designated $+45^{\circ}$ joint as shown in Fig. 5 , and the other joint has the web of the $C$ section at the outside of the $45^{\circ}$ angle will designated $-45^{\circ}$ again as shown in Fig. 5.

The behaviour of a joint is different when it is subjected to tension or compression. So combining both variables, there are six different situations to analyse for each type of frame: $90^{\circ},+45^{\circ}$ and $-45^{\circ}$, all in tension and in compression. In this paper the $90^{\circ}$ and $+45^{\circ}$ joints are analysed experimentally and all the joints numerically with finite elements for the two types of columns. The joints experimentally tested have been obtained by cutting them from an already welded frame, to guarantee that the geometry and the welds are exactly the same as in the frame.

The experimental setup can be seen in Figs. 6-8. In all the cases, two bases are mounted at both ends of the upright. The bases have a pin, passing through the centre of gravity of the section. One end is pinned and the other end is sliding pinned. With this setup, it is guaranteed that the upright is subjected always to statically determined bending.

In all tests, the brace is kept vertical. When the angle is $90^{\circ}$ the column is mounted horizontally. When the angle is $45^{\circ}$, the column is mounted diagonally at $45^{\circ}$. The load is applied to the brace by means of a hydraulic cylinder through a spherical bearing. When a tension load is applied, the cylinder is pinned at both ends. When a compression load is applied, the far end of the cylinder is fixed and the brace is laterally restrained so that only vertical movement is free.

The force applied to the brace is measured by means of a force transducer. The displacement is measured at various points (see Figs. 7 and 8) perpendicular to the web of the column at the mid span (ms) and at both sides at $225 \mathrm{~mm}$ from the mid span (f and r), the vertical (b) and the horizontal (h) displacement of the brace. All the displacements, except (h), are measured with two transducers, at both sides of the section to cancel the effects of asymmetries or rotations. The displacements are measured with displacement transducers.

With zero force, the displacement transducers are set to zero. Then the load is gradually increased until the joint reaches the failure load. The values of the force and the displacements are continuously recorded. Three samples have been tested for each situation, and the mean has been calculated. From the experimental data the joint deformation (spring) is calculated:

spring $=\mathrm{b}-\mathrm{ms}\left(\right.$ for $\left.90^{\circ}\right)$ spring $=\mathrm{b}-\mathrm{wb}\left(\right.$ for $\left.45^{\circ}\right)$

An example of the curves obtained is shown in Fig. 9. The secant stiffness of the spring curve is determined for a value of force in the brace corresponding to a displacement of $\mathrm{H} / 200=14.5 \mathrm{~mm}$ in the node of the frame where the force is applied. The mean values of the three tests for each type of joint and force are presented in Table 3. The failure forces $\left(\mathrm{F}_{\mathrm{u}}\right)$ and the failure modes of the joints are summarized in Table 4.

This experimental set-up can be used to determinate the stiffness of brace to upright welded joints. The only question to be respected is that the boundary conditions do not affect the development of the local deformations in the joint. According to the geometry of the failures observed in the tests and in the FE models, this is achieved if the ends of the upright are at a distance of the joint 2 or 3 times the height of the upright section. The length of the samples used ( 8 times the height of the upright section) is sufficient to not influence the behaviour of the joints tested. 


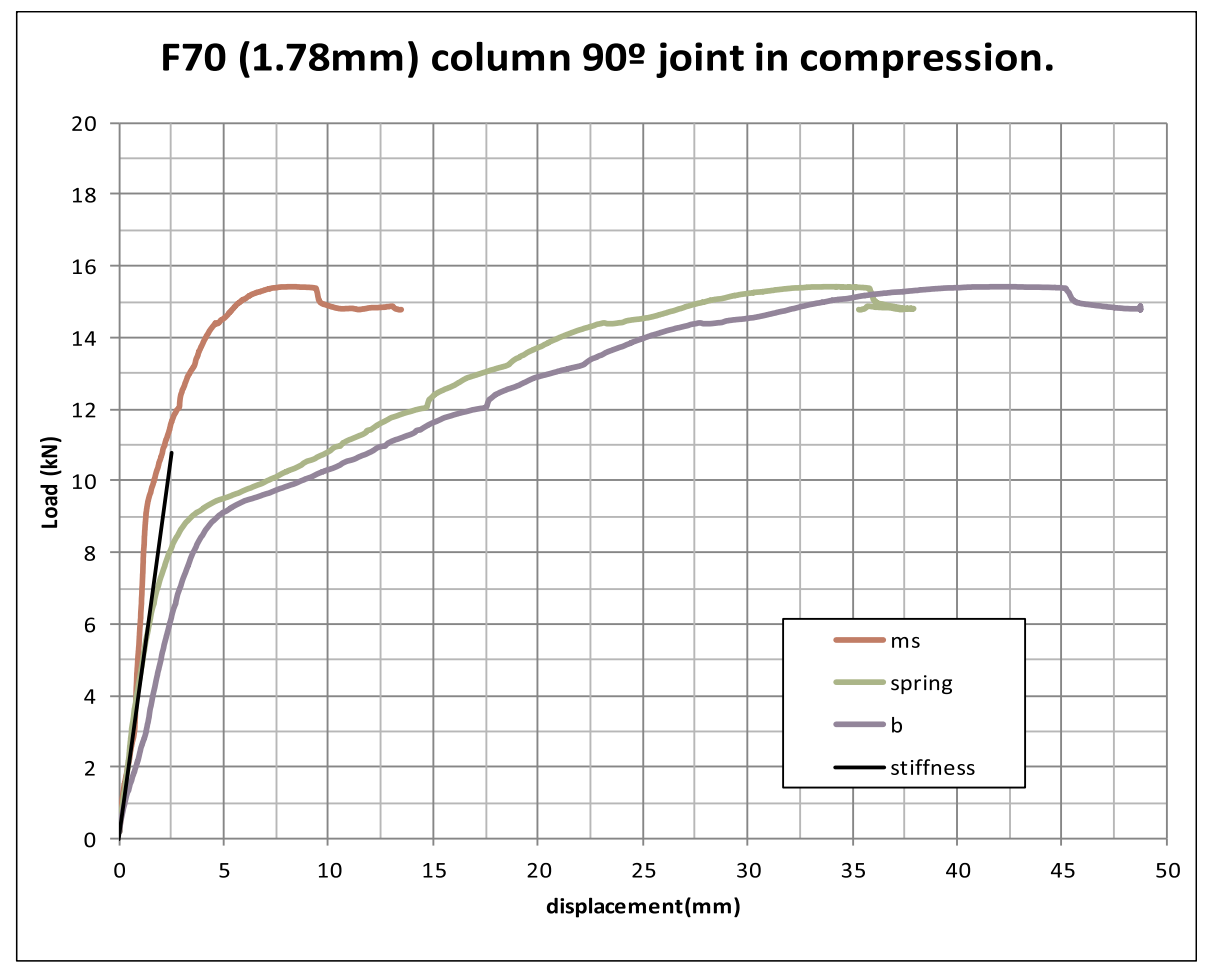

Fig. 9. F70, $90^{\circ}$ joint, compression test.

Table 3

Stiffness of the joints, obtained experimentally.

\begin{tabular}{llll}
\hline Column & Angle & Test & Stiffness $(\mathrm{N} / \mathrm{mm})$ \\
\hline F70 $(1.78 \mathrm{~mm})$ & $90^{\circ}$ & Tension & 4759 \\
& & Compression & 4171 \\
& $45^{\circ}$ & Tension & 8424 \\
& & Compression & 7700 \\
F77 $(2.67 \mathrm{~mm})$ & $90^{\circ}$ & Tension & 13948 \\
& & Compression & 12565 \\
& $45^{\circ}$ & Tension & 25715 \\
& & Compression & 18160
\end{tabular}

\section{Joint finite element analysis}

To analyse the behaviour of the joint analytically, a shell finite element model has been created using ANSYS V14. The joint has been modelled with a fine mesh of Shell 181 elements, as seen in Fig. 10. Shell 181 is a 4-node 3D shell element, suited for analyzing moderately thick shell structures. Each node has six degrees of freedom (three displacements and three rotations). The shell elements used are $3 \times 3 \mathrm{~mm}$. Based on the experience in previous simulations, a minimum of 3 elements per half wavelength of the deformed cross-section shape are needed to correctly reproduce its behaviour. In this model 6 elements have been used to simulate the lip of the upright section (see Fig. 10), thus guaranteeing the correct response of the FE model. A reduced integration option has been used. The welds between column lips and braces had to be reproduced in a realistic manner. It is not enough to connect the corresponding nodes of both components, it is necessary to reproduce the actual shape of the weld to model the connection, because it affects the stiffness of the lip of the column, which affects the stiffness of the joint. A weld with a rectangular triangle section, $3 \times 3 \mathrm{~mm}$ has been used in the FE model. The model includes material non-linearity and large displacements. For the weld, the same material model as for the brace has been used. In Fig. 11 the F$\mathrm{d}$ (displacement) curve obtained with the FE model is compared to the experimental F-d curves. In the initial part of the curves, the agreement between both methods is very good. There is also good agreement in the ultimate load. The differences in displacement in the second part of the curve (the nonlinear part) are probably because cracks appear at the welds (see Fig. 12), which are not considered in the FE model. In Table 5, the values of the stiffness of the joints obtained experimentally and with FEM are compared. In all the cases, the stiffness is calculated for a force producing a frame displacement of $\mathrm{H} / 200=14.5 \mathrm{~mm}$. The $-45^{\circ}$ joints were not tested experimentally, so there are only the FEM results available.

As can be seen in the plots in Figs. 11 and 12 as well as the results summarized in Table 5, the agreement between the FEM simulation and the experimental tests is very good. So the FEM simulation, as it has been done here, has been validated as a reliable way of analysing the behaviour of the joints.

From the experimental results and the FE results, it can be seen that the stiffness of joints subjected to tension is always higher than the stiffness of joints subjected to compression. In our opinion this is due to the difference in the joint deformation mechanisms (see Fig. 12): in tension the lips are bent upwards and the tension of the flanges causes 
Table 4

Failure force and failure mode of the joints.

\begin{tabular}{|c|c|c|c|c|}
\hline Column & Angle & Test & $\mathrm{F}_{\mathrm{u}}(\mathrm{kN})$ & Failure mode \\
\hline \multirow{4}{*}{ F70 $(1.78 \mathrm{~mm})$} & $90^{\circ}$ & Tension & 25.97 & Column lips-brace weld breaking \\
\hline & & Compression & 15.23 & Excessive deformation of column lips \\
\hline & $45^{\circ}$ & Tension & 35.00 & Column lip tearing \\
\hline & & Compression & 21.62 & Column lip tearing and brace buckling \\
\hline \multirow[t]{4}{*}{ F77 $(2.67 \mathrm{~mm})$} & $90^{\circ}$ & Tension & 35.07 & Column lip tearing or brace breaking \\
\hline & & Compression & 21.45 & Excessive deformation of column lips \\
\hline & $45^{\circ}$ & Tension & 49.90 & Brace breaking \\
\hline & & Compression & 27.64 & Column lip tearing and brace buckling \\
\hline
\end{tabular}

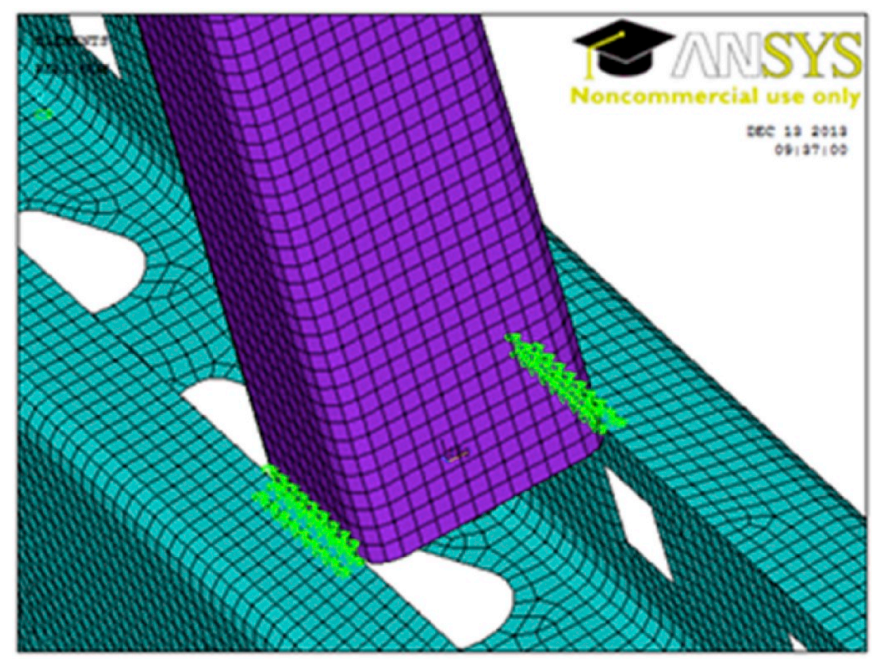

Fig. 10. FEM model: detail of the welds.

local buckling of the web, in compression the lips are bent downwards and cause local buckling of the flanges.

\section{Frame FEM modelling including the axially semi-rigid joint behaviour}

The behaviour of the rack upright frames under cross-aisle loads is limited by the maximum permissible sway of the structure. The acceptable sway values of the structure $(\mathrm{H} / 200)$ imply that only the initial part of the stiffness curve of the frame under shear is of interest. Thus, only the initial part of stiffness curves of the joints is of interest. Both can be approximated linearly and so the simulation of the frame is kept very simple and still accurate.

To improve the FEM model of the frame by taking into account the real behaviour of the joints, a fictitious beam element that simulates the axial stiffness of the joint is introduced at both ends of each brace. In Fig. 13 both FEM models are represented: a) the rigid model, with rigid joints, already analysed in Section 3; b) the semi-rigid model, with fictitious elements added to reproduce the real stiffness of the joints.

The fictitious elements added have the following characteristics:

- The axial stiffness is the stiffness of the joint, obtained with FEM model for each type of joint.

- The bending and shear stiffness of the fictitious element is the same as the brace.

- The length of the fictitious element has been chosen as the distance from the lips of the upright to the centroid of the section. Thus, the elements "braces" have exactly the same length as the actual braces. The length of the fictitious element (the spring element) could be any: the only parameter that counts is its stiffness. It was decided to give this length (and adjust the area of the section to obtain the desired axial stiffness) so that the brace in the model has exactly the same length as in the actual frame.

Linear beam elements, with these characteristics, have been added at the ends of each brace. The material has been defined with linear elastic behaviour. Small displacements of the structure are assumed.

The model with semi-rigid joints has a stiffness much closer to the experimental results than the initial model with rigid joints, as can be seen in Fig. 14 and in Table 6. The introduction of the axial flexibility of the joints in the FEM model produces a significant improvement of the results, as can be seen comparing the orange line (ANSYS rigid) and the green line (ANSYS semi-rigid), with the blue line (Experimental secant), in Fig. 14.

The semi-rigid model is useful to predict the cross aisle stiffness of the rack: an estimated difference with the actual frame $<10 \%$, and with an affordable level of complexity, using only beam elements, linear material and geometrical behaviour.

\section{Influence of the column axial load on the joint behaviour}

In an actual upright frame, the lateral forces may act simultaneously with the gravity loads of the pallets. The gravity loads of the pallets introduce high compression axial forces on the columns. Using the same models of the joints described in Section 5, a series of shell FEM simulations were carried out to find out the effect of the axial force on the stiffness and/or the behaviour of the joints.

The axial load on the upright was introduced first, and then the axial load on the brace (tension or compression) is increased gradually, until the failure of the joint. Three different levels of axial load have been used for both types of upright: $22241 \mathrm{~N}, 44483 \mathrm{~N}$ and $66724 \mathrm{~N}$ (These levels correspond, respectively, to 5000, 10000 and $15000 \mathrm{lbs}$ ). The failure of the frame under compression occurs at an axial load (per column) of $83538 \mathrm{~N}$ for F70 and $127400 \mathrm{~N}$ for F77. Therefore, the three levels cover the range of useable axial loads for both sections.

The results obtained with the FEM simulation are shown in Fig. 15. Each plot shows the experimental curve (where available) and the FEM simulation curve without axial load and with the three different levels 

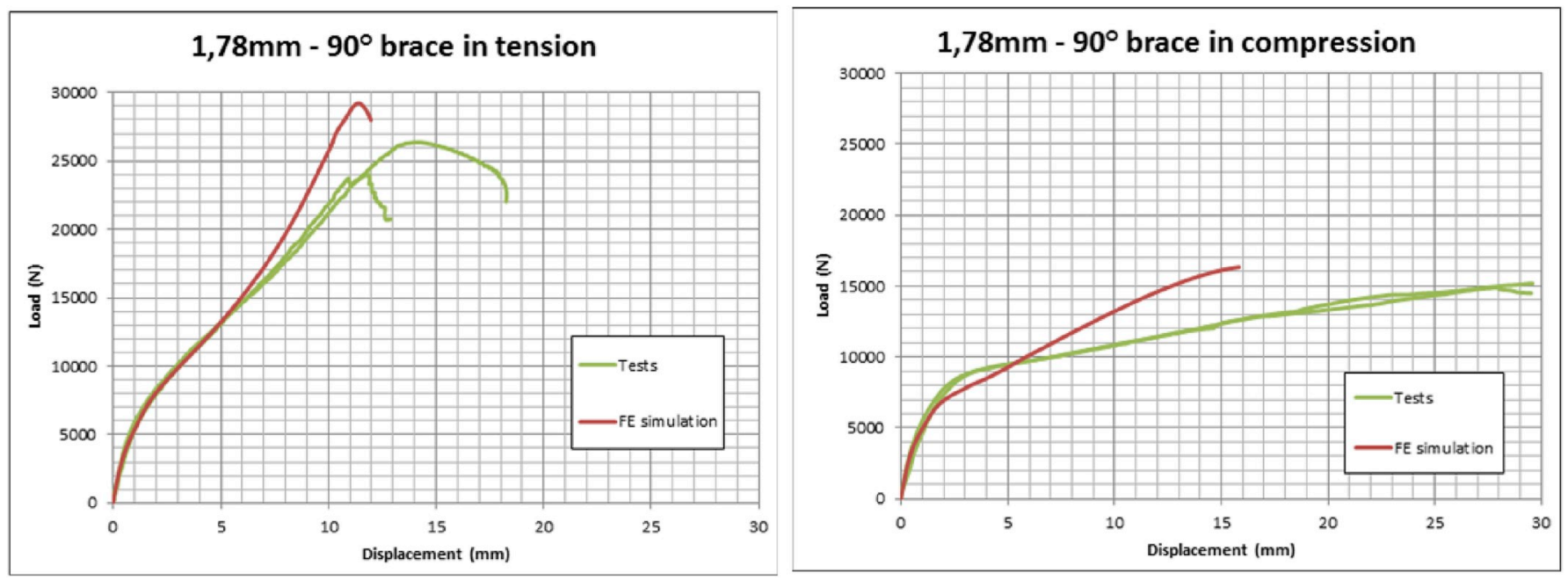

Fig. 11. Comparison of FEM and experimental displacement results.
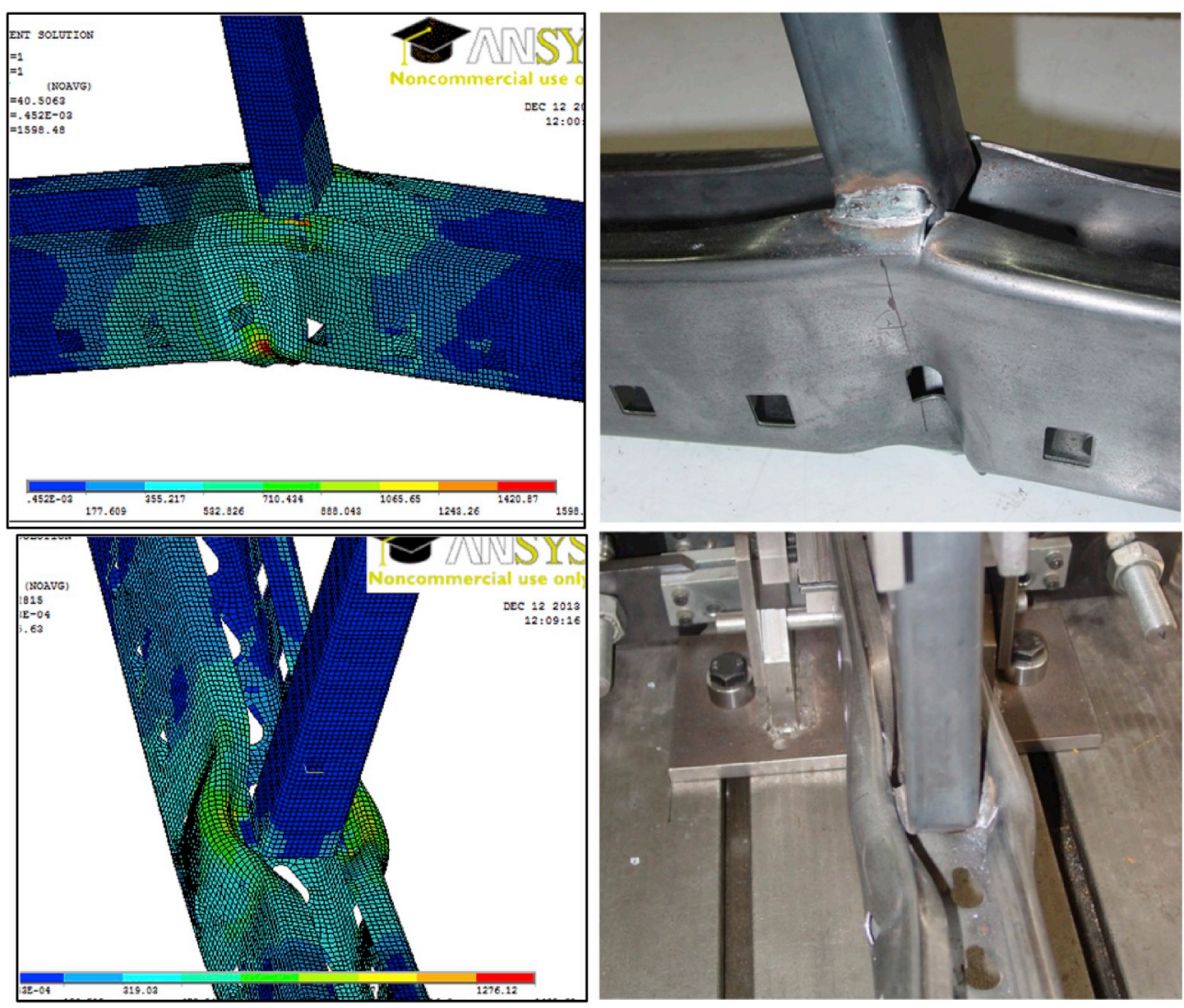

Fig. 12. Comparison FE - experimental failure mode of the $90^{\circ}$ joint in tension and compression. 
Table 5

Comparison of experimental and FEM values of joints.

\begin{tabular}{|c|c|c|c|c|c|c|}
\hline Upright & Angle & Test & $\mathrm{F}_{\mathrm{H} / 200}(\mathrm{~N})$ & $\mathrm{K}_{\text {experiment }}(\mathrm{N} / \mathrm{mm})$ & $\mathrm{K}_{\mathrm{FEM}}(\mathrm{N} / \mathrm{mm})$ & Difference (\%) \\
\hline \multirow[t]{6}{*}{ F70 $(1.78 \mathrm{~mm})$} & $90^{\circ}$ & Tension & 6870 & 4759 & 4784 & 0.5 \\
\hline & & Compression & 6879 & 4171 & 3768 & -9.7 \\
\hline & $45^{\circ}$ & Tension & 8902 & 8424 & 8923 & 5.9 \\
\hline & & Compression & 8881 & 7700 & 7436 & -3.4 \\
\hline & $-45^{\circ}$ & Tension & 8902 & - & 10530 & - \\
\hline & & Compression & 8881 & - & 8423 & - \\
\hline \multirow[t]{6}{*}{$\mathrm{F} 77(2.67 \mathrm{~mm})$} & $90^{\circ}$ & Tension & 12597 & 13948 & 14725 & 5.6 \\
\hline & & Compression & 12225 & 12565 & 13689 & 8.9 \\
\hline & $45^{\circ}$ & Tension & 15647 & 25715 & 28142 & 9.4 \\
\hline & & Compression & 16184 & 18160 & 19925 & 9.7 \\
\hline & $-45^{\circ}$ & Tension & 15647 & - & 29508 & - \\
\hline & & Compression & 16184 & - & 21120 & - \\
\hline
\end{tabular}
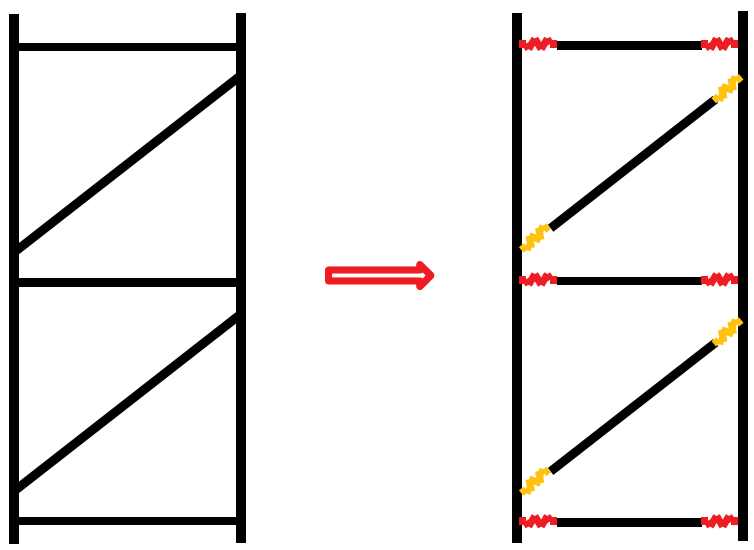

Fig. 13. FEM models of the frame with rigid and semi-rigid joints.

of axial load. In all the cases, it can be seen that the linear part (initial part) of the curve is not affected by the presence of the axial load. Table 7 shows the stiffness values of the joints, with and without axial force, calculated with the secant method described in paragraph 5 . Except for the joint F70 $90^{\circ}$, in all the other cases the reduction of the stiffness, at the highest axial load $\left(\mathrm{F}_{\mathrm{ax}}=66724 \mathrm{~N}\right)$, is lower than $10 \%$ (the mean reduction is $4.6 \%$ ).

In the second part (non-linear part) of the curve, the effect of the axial load is more important. The axial load on the upright triggers local-distortional buckling, and this interacts with the failure mechanism of the joint, governed by the deformation of the lips. The effect depends on the sense of the axial force applied to brace:

- When the brace is subjected to tension, the curve is the same, but the failure of the joint occurs at a lower load, decreasing with increasing values of the axial load in the upright.

- When the brace is subjected to compression, the curve and the failure are different, decreasing both with increasing values of the axial load in the upright.
Table 7 shows the influence of the axial load of the column on the initial stiffness of the joints, and Table 8 shows the influence of the axial load of the column on the failure load of the joints.

\section{Conclusions}

The main conclusions are:

- The in plane shear stiffness of welded frames calculated by assuming that the joints are rigid overestimates the actual frame stiffness obtained experimentally (Table 2). The reason for this difference is that the joints are not rigid and their deformations have to be taken into account.

- With the experimental set-up developed, the stiffness of the joints can be accurately measured (Table 3). The experimental set-up has to be designed to measure only the local effect, nullifying the global effects. The length of the upright and brace of the sample tested has to be enough, to guarantee that the boundary conditions do not to influence the deformations of the joint. The behaviour and stiffness in tension and compression are different from each other. The behaviour and stiffness for the joints at $90^{\circ},+45^{\circ}$ and $-45^{\circ}$ are also different from each other.

- The stiffness and behaviour of the joints can also be analysed with a FE shell model. The model has to include all geometrical details (such as the actual thickness and weld geometry), and reproduce material non-linearity and large displacements.

- The agreement between the numerical and experimental force-displacement curves of the joints is very good in the linear part of these curves (Table 5). This part is where the stiffness analysis of the frame is applied. The FE shell model accurately reproduces the failure mode of the joints (Fig. 12).

- By introducing the stiffness of the joints into the FE beam model of the frames, the stiffness of the frames agrees very well with the actual stiffness obtained experimentally (Table 6). The method has been verified with one frame geometry, two different upright sections and one brace section. There are no restrictions for using it with other frame geometries and other upright and brace sections. 

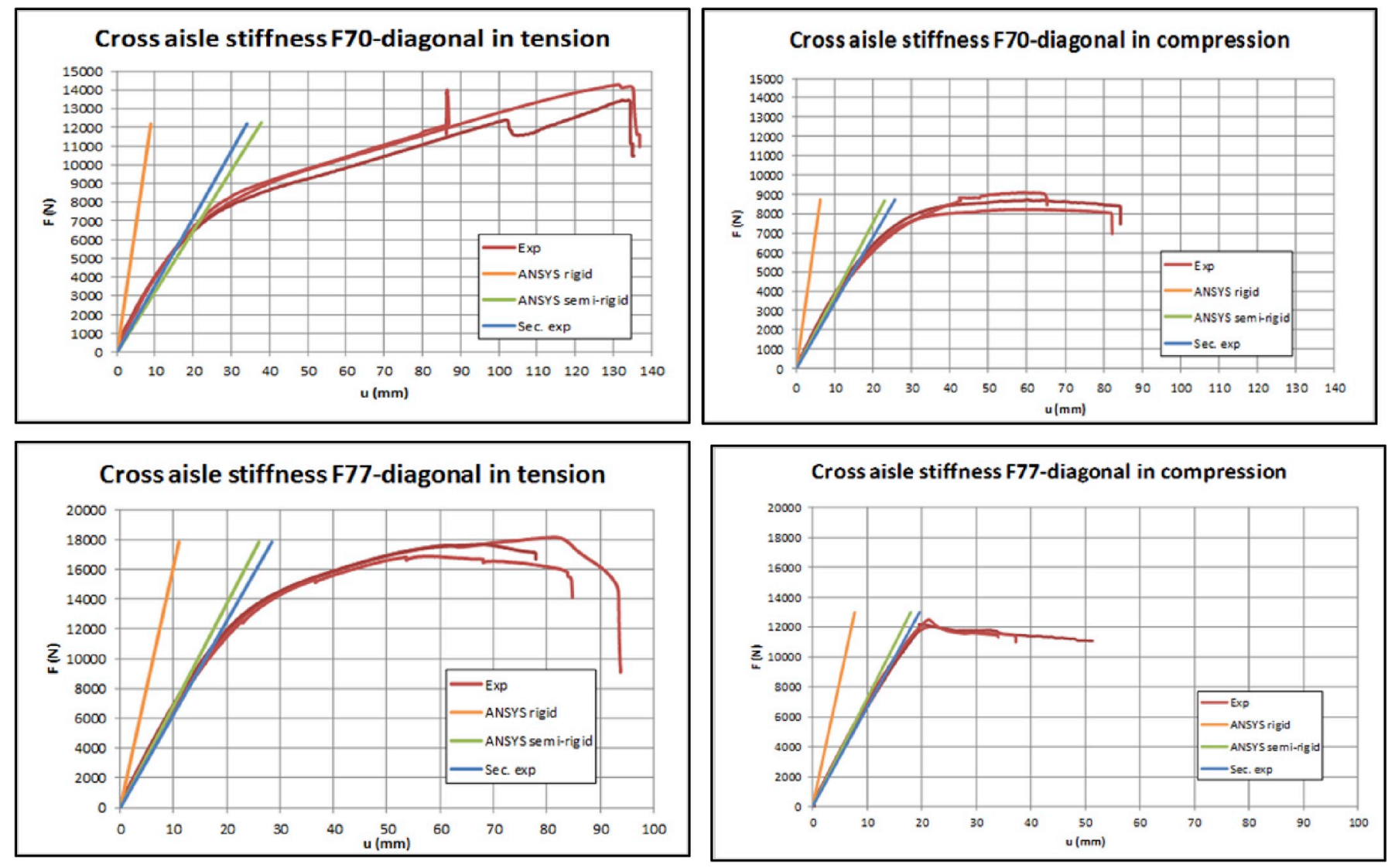

Fig. 14. Cross aisle experimental and FEM stiffness values.

Table 6

Comparison of cross-aisle stiffness of the frame, experimental and FEM semi-rigid.

\begin{tabular}{|c|c|c|c|c|}
\hline Column & Case & $\mathrm{K}_{\text {experiment }}(\mathrm{N} / \mathrm{mm})$ & $\mathrm{K}_{\mathrm{FEM}}$, semirigid $(\mathrm{N} / \mathrm{mm})$ & Difference (\%) \\
\hline \multirow[t]{2}{*}{ F70 $(1.78 \mathrm{~mm})$} & Diagonals in tension & 358 & 323 & -9.9 \\
\hline & Diagonals in compression & 356 & 378 & 6.0 \\
\hline \multirow[t]{2}{*}{ F77 $(2.67 \mathrm{~mm})$} & Diagonals in tension & 635 & 685 & 7.8 \\
\hline & Diagonals in compression & 657 & 721 & 9.8 \\
\hline
\end{tabular}

In each case, the stiffness of the brace to upright joints have to be determined either experimentally or by simulation with FE.

- The maximum sway accepted as service limit of the frames (usually $\mathrm{H} / 200$ ) is always a point in the linear part of the force - displacement curve of the frames. Thus the analysis of the stiffness of the frame can be done with a linear model, only the linear part of the stiffness of the joints is needed, and buckling of the uprights or the braces needs not to be considered.

- Numerical simulation has shown that the axial force acting on the upright reduces the stiffness in the linear part of the force-displacement curves of the brace-column joints by less than $10 \%$, except in one case (Table 7), and significantly reduces the failure load of the brace-column joints (between $27 \%$ and 60\%) (Table 8 ).
- Only the stiffness of the linear part is used to analyse the shear stiffness of the frame, so the influence of the axial force can be neglected.

\section{Acknowledgments}

The author Jordi Bonada is a Serra Húnter Fellow. The authors wish to thank the technicians Juan Espada and Francesc J. García for their skilled work in the experimental testing. The authors wish to thank RMI Specification Advisory Committee for their support. The authors wish also to thank Mecalux S. A. for providing the samples for the tests. 

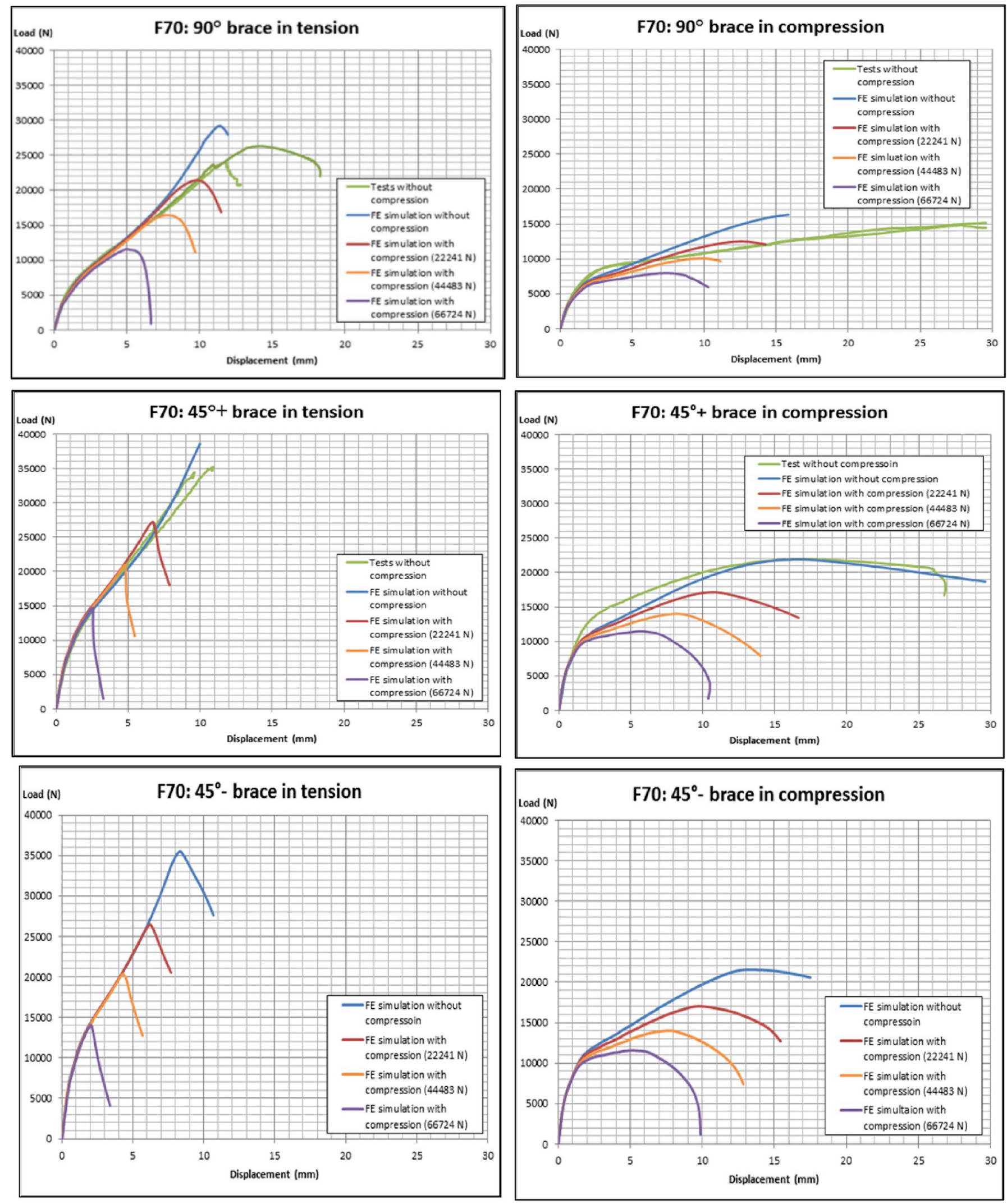

Fig. 15. Influence of the column axial load on the stiffness of the joints. 
Table 7

Influence of the column axial load on the stiffness of the joints.

\begin{tabular}{|c|c|c|c|c|c|c|c|c|c|}
\hline \multirow[t]{2}{*}{ Column } & \multirow[t]{2}{*}{ Angle } & \multirow[t]{2}{*}{ Test } & \multirow{2}{*}{$\frac{\mathrm{F}_{\mathrm{ax}}=0(\mathrm{~N})}{\mathrm{K}(\mathrm{N} / \mathrm{mm})}$} & \multicolumn{2}{|c|}{$\mathrm{F}_{\mathrm{ax}}=22241(\mathrm{~N})$} & \multicolumn{2}{|c|}{$\mathrm{F}_{\mathrm{ax}}=44483(\mathrm{~N})$} & \multicolumn{2}{|c|}{$\mathrm{F}_{\mathrm{ax}}=66724(\mathrm{~N})$} \\
\hline & & & & $\mathrm{K}(\mathrm{N} / \mathrm{mm})$ & $\Delta(\%)$ & $\mathrm{K}(\mathrm{N} / \mathrm{mm})$ & $\Delta(\%)$ & $\mathrm{K}(\mathrm{N} / \mathrm{mm})$ & $\Delta(\%)$ \\
\hline \multirow[t]{6}{*}{ F70 $(1.78 \mathrm{~mm})$} & \multirow[t]{2}{*}{$90^{\circ}$} & Tension & 4784 & 4542 & -5.1 & 4309 & -9.9 & 4101 & -14.3 \\
\hline & & Compression & 3768 & 3367 & -10.6 & 3131 & -16.9 & 3011 & -20.1 \\
\hline & \multirow[t]{2}{*}{$45^{\circ}$} & Tension & 8923 & 8899 & -0.3 & 8734 & -2.1 & 8617 & -3.4 \\
\hline & & Compression & 7436 & 7402 & -0.5 & 7321 & -1.5 & 7212 & -3.0 \\
\hline & \multirow[t]{2}{*}{$-45^{\circ}$} & Tension & 10530 & 10108 & -4.0 & 10021 & -4.8 & 9949 & -5.5 \\
\hline & & Compression & 8423 & 8159 & -3.1 & 7920 & -6.0 & 7700 & -8.6 \\
\hline \multirow[t]{6}{*}{ F77 $(2.67 \mathrm{~mm})$} & \multirow[t]{2}{*}{$90^{\circ}$} & Tension & 14725 & 14577 & -1.0 & 14444 & -1.9 & 14205 & -3.5 \\
\hline & & Compression & 13689 & 13571 & -0.9 & 13427 & -1.9 & 13332 & -2.6 \\
\hline & \multirow[t]{2}{*}{$45^{\circ}$} & Tension & 28142 & 27786 & -1.3 & 27453 & -2.4 & 27052 & -3.9 \\
\hline & & Compression & 19925 & 19683 & -1.2 & 19337 & -3.0 & 19029 & -4.5 \\
\hline & \multirow[t]{2}{*}{$-45^{\circ}$} & Tension & 29508 & 29340 & -0.6 & 29171 & -1.1 & 28994 & -1.7 \\
\hline & & Compression & 21120 & 20963 & -0.7 & 20595 & -2.5 & 19961 & -5.5 \\
\hline
\end{tabular}

Table 8

Influence of the column axial load on the failure load of the joints.

\begin{tabular}{|c|c|c|c|c|c|c|c|c|c|}
\hline \multirow[t]{2}{*}{ Column } & \multirow[t]{2}{*}{ Angle } & \multirow[t]{2}{*}{ Test } & \multirow{2}{*}{$\begin{array}{l}\mathrm{F}_{\mathrm{ax}}=0(\mathrm{~N}) \\
\mathrm{F}_{\mathrm{u}}(\mathrm{N})\end{array}$} & \multicolumn{2}{|c|}{$\mathrm{F}_{\mathrm{ax}}=22241(\mathrm{~N})$} & \multicolumn{2}{|c|}{$\mathrm{F}_{\mathrm{ax}}=44483(\mathrm{~N})$} & \multicolumn{2}{|c|}{$\mathrm{F}_{\mathrm{ax}}=66724(\mathrm{~N})$} \\
\hline & & & & $\mathrm{F}_{\mathrm{u}}(\mathrm{N})$ & $\Delta(\%)$ & $\mathrm{F}_{\mathrm{u}}(\mathrm{N})$ & $\Delta(\%)$ & $\mathrm{F}_{\mathrm{u}}(\mathrm{N})$ & $\Delta(\%)$ \\
\hline \multirow[t]{6}{*}{ F70 $(1.78 \mathrm{~mm})$} & \multirow[t]{2}{*}{$90^{\circ}$} & Tension & 29247 & 21429 & -26.7 & 16482 & -43.6 & 11602 & -60.3 \\
\hline & & Compression & 15494 & 12561 & -18.9 & 10045 & -35.2 & 7981 & -48.5 \\
\hline & \multirow[t]{2}{*}{$45^{\circ}$} & Tension & 33578 & 27285 & -18.7 & 20936 & -37.6 & 14691 & -56.2 \\
\hline & & Compression & 21907 & 17157 & -21.7 & 14071 & -35.8 & 11449 & -47.7 \\
\hline & \multirow[t]{2}{*}{$-45^{\circ}$} & Tension & 35052 & 26403 & -24.7 & 20361 & -41.9 & 13989 & -60.1 \\
\hline & & Compression & 21595 & 17006 & -21.3 & 14013 & -35.1 & 11548 & -46.5 \\
\hline \multirow[t]{6}{*}{ F77 $(2.67 \mathrm{~mm})$} & \multirow[t]{2}{*}{$90^{\circ}$} & Tension & 39274 & 33185 & -15.5 & 28591 & -27.2 & 24263 & -38.2 \\
\hline & & Compression & 24056 & 21224 & -11.8 & 18824 & -21.7 & 16583 & -31.1 \\
\hline & \multirow[t]{2}{*}{$45^{\circ}$} & Tension & 45123 & 39726 & -12.0 & 33859 & -25.0 & 28467 & -36.9 \\
\hline & & Compression & 31301 & 28179 & -10.0 & 25188 & -19.5 & 22524 & -28.0 \\
\hline & \multirow[t]{2}{*}{$-45^{\circ}$} & Tension & 43979 & 38172 & -13.2 & 33035 & -24.9 & 27934 & -36.5 \\
\hline & & Compression & 31161 & 28134 & -9.7 & 25178 & -19.2 & 22599 & -27.5 \\
\hline
\end{tabular}

\section{References}

[1] L. Bertocci, D. Comparini, G. Lavacchini, M. Orlando, L. Salvatori, P. Spinelli, Experimental, numerical, and regulatory P-Mx-My domains for cold-formed perforated steel uprights of pallet-racks, Thin-Walled Struct. 119 (2017) 151-165.

[2] L. Dai, X. Zhao, K.J.R. Rasmussen, Flexural behaviour of steel storage rack beam-to-upright bolted connections, Thin-Walled Struct. 124 (2018) 202-217.

[3] B. El Kadi, C. Coşgun, A. Mangır, G. Kıymaz, Strength upgrading of steel storage rack frames in the down-aisle direction, Steel Compos. Struct. 23 (2) (2017) 143-152.

[4] S.N.R. Shah, N.H.R. Sulong, M.Z. Jumaat, M. Shariati, State-of-the-art review on the design and performance of steel pallet rack connections, Eng. Fail. Anal. 66 (2016) $240-258$.

[5] S.N.R. Shah, N.H.R. Sulong, M. Shariati, M.Z. Jumaat, Steel rack connections: identification of most influential factors and a comparison of stiffness design method, PLoS One 10 (10) (2015) e0139422.

[6] S. Shah, N.R. Sulong, M. Shariati, R. Khan, M. Jumaat, Behavior of steel pallet rack beamto-column connections at elevated temperatures, Thin-Walled Struct. 106 (2016) $471-483$.

[7] S.N.R. Shah, N.H.R. Sulong, R. Khan, M.Z. Jumaat, M. Shariati, Behavior of industrial steel rack connections, Mech. Syst. Signal Process. 70-71 (2016) 725-740.

[8] M. Shariati, M.M. Tahir, T.C. Wee, S.N.R. Shah, A. Jalali, M.M. Abdullahi, M. Khorami, Experimental investigations on monotonic and cyclic behavior of steel pallet rack connections, Eng. Fail. Anal. 85 (2018) 149-166.

[9] X. Zhao, L. Dai, T. Wang, K.S. Sivakumaran, Y. Chen, A theoretical model for the rotational stiffness of storage rack beam-to-upright connections, J. Constr. Steel Res. 133 (2017) 269-281.

[10] F. Gusella, G. Lavacchini, M. Orlando, Monotonic and cyclic tests on beam-column joints of industrial pallet racks, J. Constr. Steel Res. 140 (2018) 92-107.

[11] M. Orlando, G. Lavacchini, B. Ortolani, P. Spinelli, Experimental capacity of perforated cold-formed steel open sections under compression and bending, Steel Compos. Struct. 24 (2) (2017) 201-211.

[12] S. Sambasiva, R.G. Beale, M.H.R. Godley, Shear stiffness of pallet rack frames, Proceedings of the 7th International Specialty Conference on Cold-Formed Structures, 2004, pp. 295-311.

[13] S.R. Sajja, R.G. Beale, M.H.R. Godley, Shear stiffness of pallet rack upright frames, J. Constr. Steel Res. 64 (2008) 867-874.

[14] RMI, ANSI MH 16.1: 2008, Specification for the Design, Testing and Utilization of Industrial Steel Storage Racks, Materials Handling Industry of America (MHIA), Charlotte, USA, 2008.

[15] B.P. Gilbert, K.J.R. Rasmussen, N. Baldassino, T. Cudini, L. Rovere, Determining the transverse shear stiffness of steel storage rack upright frames, J. Constr. Steel Res. 78 (2012) 107-116.

[16] F. Roure, M.R. Somalo, J. Bonada, M.M. Pastor, M. Casafont, Down-aisle stiffness of steel shelving structures: experimental and FE approach, $8^{\text {th }}$ International Conference on Advances in Steel Structures, 2015.

[17] F. Roure, T. Peköz, J. Bonada, M.R. Somalo, M.M. Pastor, M. Casafont, Stiffness of welded brace to lipped channel column joints: an experimental and numerical approach, International Colloquium on Stability and Ductility of Steel Structures, 2016.

[18] F. Roure, T. Peköz, J. Bonada, M.R. Somalo, M.M. Pastor, M. Casafont, Design of industrial cold-formed steel rack upright frames for loads in cross-aisle direction, International Conference on Cold-Formed Steel Structures, 2016.

[19] H. Far, A. Saleh, A. Firouzianhaji, A simplified method to determine shear stiffness of thin walled cold formed steel storage rack frames, J. Constr. Steel Res. 138 (2017) 799-805. 